\title{
A Supply Chain Product Delivery and Distribution Planning Model
}

\author{
Kanchan Das \\ Technology Systems Department, East Carolina University, \\ Greenville, NC 27858-4353, USA \\ Email: dask@ecu.edu \\ R.S. Lashkari \\ Department of Industrial Engineering, University of Windsor, \\ Windsor, ON N9B 3P4 Canada \\ E-mail: lash@uwindsor.ca (Corresponding Author)
}

\begin{abstract}
We propose a mixed integer program (MIP) based product distribution planning model for optimizing the transportation and distribution cost of a supply chain. The model takes into account production/procurement centers (PCs) and plans product delivery to customers either directly from the PCs, or through distribution centers (DCs) considering the available distribution modes. To cover the customer requirements at diverse geographic regions, the model selects optimum regions for DCs, and determines the capacities and the number of DCs to be used in each region to achieve optimum cost. Within the possible distribution modes, the model explores options of using distribution contractors (e.g., the U.S. post office; FedEx, UPS, etc.). A numerical example illustrates the applicability of the model.
\end{abstract}

Keywords: distribution planning, production/procurement centers, MIP modeling, distribution modes, regional distribution centers, supply chains.

\section{INTRODUCTION}

Given the current internet-based business operations, ensuring timely receipt of the products ordered by a customer is an essential requirement for a SC to be competitive in the market. This timely receipt may be considered by the businesses as a performance metric for making service differentiation. This is because there is little difference in terms of the availability of product variety, quality, price, and product presentation among the e-market based businesses. E-market based supply chains (SCs) are similar to two phase retail network SCs as described in Jayaraman and Ross (2003) where the cost of product delivery may be considered to be a differentiating factor in the overall cost structure of the SC, and where the customer satisfaction parameters are highly dependent on the coordination of the customer demand and effective distribution planning. With the help of modern SC management software, scheduling the delivery of customer orders and planning for product realization/procurement may be performed very efficiently. However, the choice of the regions where the distribution centers (DCs) are to be located and the possible distribution modes to deliver the products according to the orders is still crucial (Lasserre,
2004). Considering that customer satisfaction is the main determinant for the overall business performance, a SC decides whether a product should be: a) sent directly to the customer by courier services; b) accumulated for a number of orders and then transported to regional DCs from where it will be sent to the customer, or to suitable customer pickup centers (markets); c) sent to the customer following both a) and b) based on the customer preferences. Each option is to be considered based on the number of regions, the number of DCs in a region, the size of DCs, the location of customer pick up points (or markets); transportation costs; distances from PCs to DCs and from DCs to customer regions; market demand; and the comparison of costs for courier and other distribution modes. All these factors should be taken into account to ensure the overall SC performance improvement and the desired customer satisfaction. Based on the above discussion, we propose an approach to the problem which incorporates the desired business performance objectives and the various operational factors in a mathematical model. The paper proposes a mixed integer programming (MIP) model that includes all the factors discussed above in order to decide on the number of regions, the number and capacity of the DCs, the choice of the suitable distribution options (SC's own distributions and courier services), to achieve the business objectives at the optimum cost.

The remainder of the paper is organized as follows. Section 2 reviews the relevant literature. Section 3 includes the problem statement, notations, and the formulation of the mathematical model. Section 4 illustrates a numerical example to show the applicability of the model, and discusses the results. Some concluding remarks are presented in Section 5.

\section{LITERATURE REVIEW}

Most of the SC literature addresses distribution planning as a part of the production-distribution planning problem of a SC (Vidal and Goetschalckx, 1997; Jayaraman and Pirkul, 2001; Dasci and Verter, 2001; Manzini et al, 2014). Recent research in this area addresses distribution network design from the viewpoint of locating DCs and allocating customers to DCs (Jayaraman and Ross, 2003). The geographical allocation problem may be considered 
common in the two approaches to the problem. Jayaraman and Ross (2003) addressed the distribution network design for retail chains to optimize the distribution costs where the products are obtained from globally located suppliers.

Distribution networks are the mechanism through which products reach customers in the modern business environment. Thomas and Wilkinson (2006) appropriately mentioned distribution as the valuable way of the 20th century business to gain market share, and gave examples of food and chemical companies (e.g., Proctor and Gamble, Colgate-Palmolive-Peet Co.) that utilize wholesalers for distribution. The production/procurement centers (PCs) defined in the present research play a similar role as the wholesalers in Thomas and Wilkinson (2006).

Since marketing and distribution are interlinked considering the overall business perspectives, several research works as well as some practitioners advocate a combination of distribution networks, such as physical retail stores and e-marketing for displaying product to consumer to improve the overall business performance (Agatz et al., 2008). This multi-channeling reduces the e-fulfillment cost by creating synergies. However, distribution has been identified as the most critical operation and its cost stated to be the highest for such distribution businesses (Lummus and Vokurka, 2002). In this multi-channeling-based business environment (popularly called brick-and-click) the coordination of the participating organizations for product distribution as well as for using the common coordinated online market for the same or similar products are said to generate improved profit (Yan et al., 2011).

In addition to costs for allocation and sourcing of products (suppliers, manufacturers), selection of transportation modes, and decision of vehicles routing influence operations cost for product distribution (Manzini et al. 2014). Simchi-Levi (1992) presented distribution planning models to determine the number of DCs and the regions where they are sited, the allocation of customers to regions, and the vehicle routing strategies to optimize the total cost assuming that the number of customers and their demands are probabilistically distributed. These situations are quite applicable to present day e-market distribution systems.

The literature also includes studies where products are directly delivered or distributed to the customers from the production/procurement centers (Chen and Vairakatarakis, 2005). Such practices are applicable in production-to-order businesses where production and scheduling is integrated in order to meet the customer delivery deadlines. Such direct delivery is also applicable in e-markets where products are directly sent to customer by courier services or other distribution modes.

Liu and Papageorgiou (2013) proposed a multiobjective model to decide the capacity expansions and to optimize the SC performance, emphasizing that in distribution planning, the distribution cost, the customer response time, and the customer service level are important trade-off parameters.

The literature review establishes the importance of distribution planning for optimum business performance. It also reveals a gap for a systematic model-based research effort to address the emerging e-market situations where the decision is to determine the number and capacities of DCs; the location of customer pick-up centers; the allocation of customers covered by DCs; and distribution modes for timely delivery to customers. This research is a contribution towards the elimination of that gap.

\section{PROBLEM STATEMENT}

Figure 1 displays the schematic diagram of the supply chain under consideration. We assume that a set of products $\mathrm{i}(\mathrm{i} \in \mathrm{I})$ is realized by a supply chain (SC) at a set of production or procurement centers $P C_{j}(j \in J)$. There is a random demand $D_{i m}$ for product $i$ in a set of markets $m$ $(\mathrm{m} \in \mathrm{M})$ in diverse geographical regions. To ensure product supply to market, the SC plans a set of distribution centers $\mathrm{DC}_{\mathrm{k}}(\mathrm{k} \in \mathrm{K})$ in a set of possible marketing regions $1(\mathrm{l} \in \mathrm{L})$. The $\mathrm{SC}$ has contractual arrangement with several transportation and distribution contractors who deliver the products from PCs to DCs and from DCs to customers (markets). This contractual arrangement includes per-unit rates for transportation and distribution of products based on the timely delivery of a load by the contractor, as well as the distances travelled. To deliver the products directly to market places from the PCs, the SC has the option of utilizing courier services (e.g., US postal service, UPS, FedEx, etc.) by paying the per-unit delivery charges based on the same conditions of timely delivery and distances. The demand for product $\mathrm{i}$ in market $\mathrm{m}$, Dim, is assumed to be normally distributed. The objective of the SC is to decide optimum capacity, region, number of DCs, and allocation of DCs to markets at an optimum cost. The objective of SC also includes selection of optimum distribution mode for distributing product to market.

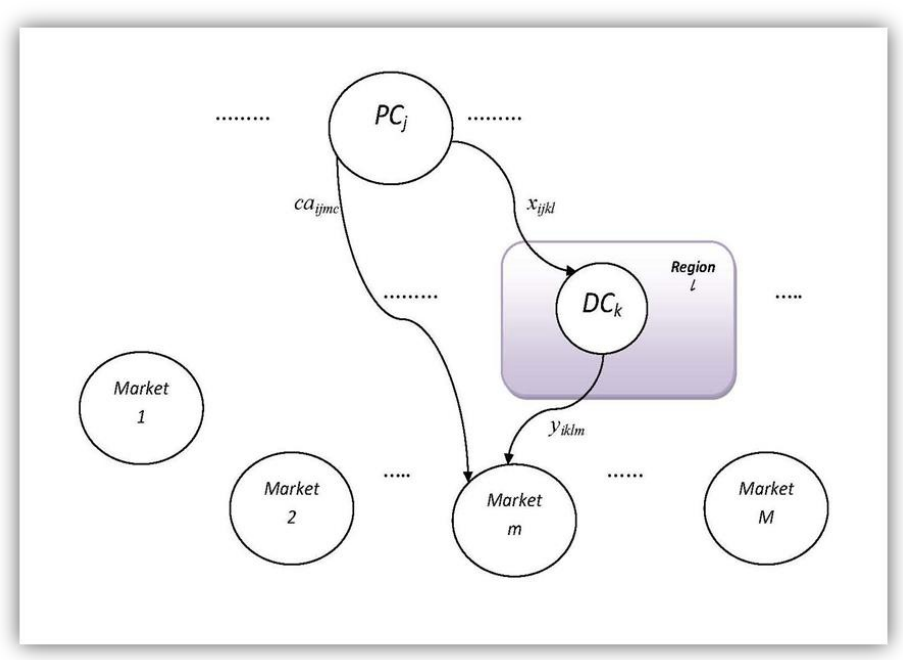

Figure 1 Schematic Diagram of the Supply Chain Under Consideration

\section{Indices}

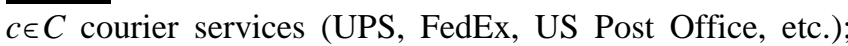
$i \in I$ products; $j \in J$ production or procurement centers for product realization; $k \in K$ distribution centers (DC); $l \in L$ regions; $m \in M$ markets.

\section{Parameters}

$B N \quad$ : large positive numbers

$C D_{j m c} \quad$ : per-unit delivery cost from PC $j$ to market $m$ by courier $c$ 
$C P R_{i j} \quad$ : capacity of PC $j$ to realize and or produce product $i$

$C R_{i j} \quad$ : average per-unit realization cost of product $i$ at PC $j$ (may include the cost of placing orders, monitoring suppliers, maintaining e-purchase agents for product procurement, patronizing and facilitating authors / innovators / importers / producers, getting certified in quality standards, cost of maintaining computers, racks, safety stocks at the PC)

$D R_{i k l m}$ : cost of distributing product $i$ from DC $k$ in region $l$ to market $m$

$F T C_{j k l} \quad$ : fixed cost of setting up transportation arrangements from $\mathrm{PC} j$ to $\mathrm{DC} k$ in region $l$

$F C C_{j m}$ : fixed cost of setting up product delivery system from PC $j$ to market $m$ through courier services

$F C D_{j} \quad$ : fixed cost of installing product delivery system from PC $j$ to be picked up by courier service

$F D_{k l m}$ : fixed cost of product distribution from DC $k$ in region $l$ to market $m$

$F P C_{j} \quad$ : fixed cost of opening PC $j$

$F W_{k l} \quad$ : fixed cost of opening DC $k$ in region $l$

$T R_{i j k l} \quad$ : per-unit transportation cost of product $i$ between $\mathrm{PC} j$ and $\mathrm{DC} k$ in region $l$

$D_{i m} \quad$ : demand for product $i$ in market $m$

NS : maximum number of markets to which a DC in a given region may be assigned

ND : maximum number of DCs that a given region may have

\section{Variables}

$y_{i k l m} \quad$ : product $i$ distributed to market $m$ from DC $k$ at region $l$

$z_{k l m} \quad: 1$, if DC $k$ in region $l$ is assigned to market $m ; 0$, otherwise

$c w_{i k l} \quad$ : capacity requirements of DC $k$ in region $l$ for product $i$

$a_{k l} \quad: 1$, if DC $k$ in region $l$ is open; 0 , otherwise

$x_{i j k l} \quad:$ units of product $i$ transported from $\mathrm{PC} j$ to $\mathrm{DC} k$ in region $l$

$u_{j k l} \quad: 1$, if $\mathrm{PC} j$ is allocated to supply DC $k$ in region $l$; 0 , otherwise

$c a_{i j m c} \quad$ : units of product $i$ distributed from PC $j$ to market $m$ by courier service $c$

$v_{j m} \quad: 1$, if PC $j$ is setup to directly supply market $m ; 0$, otherwise

$r_{j} \quad: 1$, if $\mathrm{PC} j$ is open to dispatch products through courier services and transportation contractors; 0 , otherwise

Objective: minimize TC

where $T C$ is the total cost defined in equation

$$
T C=P R C+T D C+C D C
$$

$P R C$ : cost of product realization process; TDC: cost of transporting products to DCs and distributing them to customers using transportation and distribution contractors; $C D C$ : cost of supplying products to customers through courier services.

$P R C=\sum_{i \in I} \sum_{j \in J} C R_{i j}\left(\sum_{k \in K} \sum_{l \in L} x_{i j k l}+\sum_{m \in M} \sum_{c \in C} c a_{i j m c}\right)+\sum_{j \in J} F P C_{j} r_{j}$

$$
\begin{aligned}
& T D C=\sum_{j \in J} \sum_{k \in K} \sum_{l \in L} F T C_{j k l} u_{j k l}+\sum_{i \in I} \sum_{j \in J} \sum_{k \in K} \sum_{l \in L} T R_{i j k l} x_{i j k l}+ \\
& \sum_{i \in I} \sum_{k \in K} \sum_{l \in L} \sum_{m \in M} D R_{i k l m} y_{i k l m}+\sum_{k \in K} \sum_{l \in L} F W_{k l} a_{k l} \\
& C D C=\sum_{m \in M} \sum_{j \in J}\left(F C C_{j m} v_{j m}+\sum_{c \in C} C D_{j m c} \sum_{i \in I} c a_{i j m c}\right) \\
& \sum_{k \in K} \sum_{l \in L} y_{i k l m}+\sum_{j \in J} \sum_{c \in C} c a_{i j m c}=D_{i m} \forall i, m \\
& \sum_{i \in I} y_{i k l m} \leq B N \cdot z_{k l m} \forall k, l, m \\
& \sum_{i \in I} \sum_{c \in C} c a_{i j m c} \leq B N \cdot v_{j m} \forall j, m \\
& c w_{i k l} \geq \sum_{m \in M} y_{i k l m} \forall i, k, l \\
& \sum_{i \in I} c w_{i k l} \leq B N \cdot a_{k l} \forall k, l \\
& z_{k l m} \leq a_{k l} \forall k, l, m \\
& \sum_{l \in L} a_{k l}=1 \forall k \\
& \sum_{k \in K} a_{k l} \leq N D \forall l \\
& N S \geq \sum_{m \in M} z_{k l m} \geq 1 \forall k, l \\
& \sum_{j \in J} x_{i j k l}=\sum_{m \in M} y_{i k l m} \forall i, k, l \\
& \sum_{i \in I} x_{i j k l} \leq B N \cdot u_{j k l} \forall j, k, l \\
& \sum_{m \in M} \sum_{c \in C} c a_{i j m c}+\sum_{k \in K} \sum_{l \in L} x_{i j k l} \leq r_{j} C P R_{i j} \forall i, j \\
& u_{j k l} \leq r_{j} \forall j, k, l \\
& v_{j m} \leq r_{j} \forall j, m \\
& r_{j} \in\{1,0\}, \forall j ; a_{k l} \in\{1,0\}, \forall k, l ; u_{j k l} \in\{1,0\}, \forall j, k, l ; v_{j m} \in\{1,0\}, \forall j, m ; z_{k l m} \in\{1,0\}
\end{aligned}
$$

Equation (2) computes the total cost (TC) of supplying products to customers. Components of $T C$ are defined in equations (2.a) to (2.c). The first component of $T C$ defined in equation (2.a) is the product realization cost $P R C$, which includes the cost of product realization process (described above) and the fixed cost of setting up or opening the PCs. The second component, $T D C$, equation (2.b), is the transportation and distribution cost which includes the fixed cost of setting up transportation arrangements (loading, unloading, staging, weighing, dispatch accounting, fixed cost for contractual agreement with carrier companies) at the $\mathrm{PCs}$, the transportation cost from $\mathrm{PCs}$ to $\mathrm{DCs}$, the distribution cost from DC to customers in the market, and the fixed cost of opening or setting up the DCs. The third component, CDC, as defined in equation (2.c), computes the product delivery costs using courier services. It includes the fixed cost of contractual arrangements with courier services; 
the cost of product delivery charged by the courier service (assumed to be paid by the SC), and the fixed cost of setting up PCs to handle courier delivery.

Constraint (3) balances the product supplies to the markets directly through courier services and via DCs through transportation and distribution contactors with the market demand. Constraint (4) distributes products to a market only from an DC which is allocated to that market using distribution contractors. Similarly, constraint (5) ensures the direct distribution of products from a PC, which is allocated to a market, through courier services. Constraint (6) determines the required capacity of a DC considering the product shipments to market from that DC. Constraint (7) allocates capacity to a DC that is opened in a selected region. Constraint (8) ensures that a DC is opened in a region first before it is assigned to a market. Constraint (9) ensures that a DC opens in only one region, if at all. Constraint (10) limits the number of DCs located in a region. Similarly, constraint (11) sets limits the number of markets that a DC in a region may serve. Equation (12) balances the product shipments from the PCs to DCs, against the product shipments from the DCs to the markets. Constraint (13) ensures product shipments from a PC to a DC only when the PC is assigned to supply the DC. Constraint (14) limits the product shipments from a PC, through courier services and transportation contractors, within its capacity. Constraint (15) ensures that a PC is open before any product shipments to a DC are allowed. Similarly constraint (16) ensures market shipments through courier services only from an open PC. Finally, constraint (17) imposes integrality.

\section{A NUMERICAL EXAMPLE}

We assume a SC that has 3 PCs where it receives orders for its 15 products from customers in 25 markets (or customer centers) located in five 5 regions. The SC has the option of opening as many as 8 DCs in the 5 regions with the required capacities to cover all the markets. The model requires a great deal of input data, and in turn generates a great deal of information. However, in this section, the data are only partially presented; we concentrate mainly on the model outcomes that are interesting and related to the objectives of the study. Also, we only present the input information that is needed to analyze the model outputs. The input data are randomly generated based on practical data range values.

The model was solved using the commercial solver LINGO 14 on a standard PC. It involved a total of 23,142 variables, 1,238 integer variables, 4,108 constraints, and needed from one hour to 1.5 hours to reach the global optimum solution depending on the specific situation under consideration.

Table 1 presents partial data on product demands that were estimated assuming a normal distribution of demand in various market regions. For example, there is a demand of 1,582 units for product 1 in market 1 , as may be observed in Table 1.

Table 2 presents typical per unit costs of transporting product 1 from PC1 to the DCs located in regions 1 to 5. For example, the cost of transporting product 1 from PC1 to DC1 located in region 1 is $\$ 0.55$.

Table 1 Partial Data on Product Demands in Select Markets

\begin{tabular}{|c|c|c|c|c|c|c|c|c|c|c|c|}
\hline & \multicolumn{10}{|c|}{ Typical market demands for different products } \\
\hline Market & $\mathbf{1}$ & $\mathbf{2}$ & $\mathbf{3}$ & $\mathbf{4}$ & $\mathbf{5}$ & $\mathbf{\ldots \ldots}$ & $\mathbf{1 1}$ & $\mathbf{1 2}$ & $\mathbf{1 3}$ & $\mathbf{1 4}$ & $\mathbf{1 5}$ \\
\hline 1 & 1,582 & 2,071 & 2,114 & 5,195 & 1,957 & $\ldots \ldots$. & 1,011 & 2,823 & 5,116 & 1,180 & 3,163 \\
\hline 2 & 4,191 & 6,162 & 1,197 & 958 & 2,217 & $\ldots \ldots$. & 4,251 & 6,610 & 6,395 & 4,001 & 5,134 \\
\hline 3 & 2,415 & 4,295 & 5,271 & 757 & 2,426 & $\ldots \ldots$. & 2,944 & 3,418 & 1,518 & 542 & 474 \\
\hline 4 & 748 & 4,654 & 2,683 & 2,791 & 5,230 & $\ldots \ldots$. & 6,445 & 5,788 & 1,929 & 5,453 & 577 \\
\hline 5 & 938 & 4,937 & 2,719 & 6,530 & 767 & $\ldots \ldots$. & 2,037 & 1,010 & 1,459 & 4,984 & 648 \\
\hline
\end{tabular}

Table 2 Typical Transportation Cost for Product1 from PC 1 to DCs in Various Regions

\begin{tabular}{|c|c|c|c|c|c|c|c|c|}
\hline \multirow{2}{*}{ Regions } & \multicolumn{7}{|c|}{ Typical transportation cost in for product 1 from PC1 to DCs located in regions. } \\
\cline { 2 - 9 } & $\mathbf{1}$ & $\mathbf{2}$ & $\mathbf{3}$ & $\mathbf{4}$ & $\mathbf{5}$ & $\mathbf{6}$ & $\mathbf{7}$ & $\mathbf{8}$ \\
\hline 1 & 0.55 & 1.14 & 0.98 & 0.97 & 0.76 & 1 & 0.61 & 1.1 \\
\hline 2 & 0.87 & 1.17 & 0.74 & 0.76 & 1.07 & 0.75 & 1.2 & 1.09 \\
\hline 3 & 1.02 & 0.75 & 0.66 & 0.97 & 1.16 & 0.96 & 1 & 1.17 \\
\hline 4 & 0.66 & 1.12 & 1.03 & 0.86 & 0.8 & 0.65 & 1.11 & 0.72 \\
\hline 5 & 0.70 & 0.59 & 0.71 & 1.04 & 0.61 & 0.73 & 0.61 & 1.19 \\
\hline
\end{tabular}

Table 3 Typical Distribution Cost for Product1 from DCs in Various Regions to Market 1

\begin{tabular}{|c|c|c|c|c|c|c|c|c|}
\hline \multirow{2}{*}{ Regions } & \multicolumn{7}{|c|}{ Typical distribution cost in \$ for product 1 from DCs located in region 1 to Market 1 } \\
\cline { 2 - 9 } & $\mathbf{1}$ & $\mathbf{2}$ & $\mathbf{3}$ & $\mathbf{4}$ & $\mathbf{5}$ & $\mathbf{6}$ & $\mathbf{7}$ & $\mathbf{8}$ \\
\hline 1 & 0.48 & 0.72 & 0.65 & 0.44 & 0.51 & 0.63 & 0.53 & 0.71 \\
\hline 2 & 0.44 & 0.43 & 0.44 & 0.48 & 0.57 & 0.48 & 0.43 & 0.42 \\
\hline 3 & 0.45 & 0.57 & 0.75 & 0.4 & 0.41 & 0.75 & 0.65 & 0.43 \\
\hline 4 & 0.69 & 0.74 & 0.44 & 0.7 & 0.63 & 0.63 & 0.49 & 0.7 \\
\hline 5 & 0.74 & 0.73 & 0.54 & 0.72 & 0.61 & 0.43 & 0.71 & 0.66 \\
\hline
\end{tabular}


Table 3 presents the typical costs of distributing product 1 from DCs in various regions to market 1 . For example, the cost of distributing product 1 from DC 1 in region 1 to market 1 is $\$ 0.48$, as may be observed in Table 3. Table 4 presents the typical cost of distributing a product from PC1 directly to markets (5 out of 25 shown) using courier services. For example, to directly distribute a unit of a product from PC1 to market 1 using courier service 1 costs $\$ 4.41$.

Table 4 Typical Product Distribution Cost from PC 1 to Markets by Courier Services

\begin{tabular}{|c|c|c|c|c|}
\hline \multirow{2}{*}{ Markets } & \multicolumn{4}{|c|}{ Typical cost in \$ direct distribution of a product by courier services to various markets } \\
\cline { 2 - 5 } & $\mathbf{1}$ & $\mathbf{2}$ & $\mathbf{3}$ & $\mathbf{4}$ \\
\hline 1 & 4.41 & 2.85 & 3.56 & 4.44 \\
\hline 2 & 3.85 & 4.19 & 4.11 & 4.05 \\
\hline 3 & 2.43 & 2.64 & 3.70 & 3.48 \\
\hline 4 & 4.12 & 2.25 & 3.11 & 2.92 \\
\hline 5 & 3.48 & 2.27 & 2.58 & 4.47 \\
\hline
\end{tabular}

\subsection{Model Output}

Table 5 presents model results on the allocation of PCs to the regions; the location of DCs in the regions; and the allocation of DCs and courier services to supply markets. The results in Table 5 are based on the following assumptions:

- ND = 3 in constraint (10); that is, a region may have at most 3 DCs.

- NS = 3 in constraint (11); that is, a DC in a region may serve up to 3 markets.

The results indicate that the model assigned each of the three PCs to supply products in each of the five regions. Regarding the allocation of DCs to regions, the model assigns DC 1 to region 1; DCs 2,3, and 5 to region 2; DCs 4 and 7 to region 3; and DCs 6 and 8 to region 4 . Next, the model allocated markets to DCs. For example, markets 11, 20 , and 25 are allocated to DC 1 in region 1; the allocation of the other markets to DCs may be similarly observed in Table 5. It is noted that no DC has been allocated to region 5 , and that market 5 has not been allocated to any DC; it is instead supplied directly from PC 4 using courier service 4.

Table 6 shows, as an example, the typical model results pertaining to the transportation of product 1 from PCs to DCs in various regions, and the distribution of the product from there to the markets allocated to DCs. For example, 11,797 units of product 1 is transported from PC 1 to DC 1 in region 1 , which are then distributed as follows among the markets allocated to DC 1:2,969 units to market 11 ; 4,612 units to market 20; and 4,216 units to market 25 .

Table 5 Model Decision on Allocation of PCs to Regions, Location of DCs in Regions, and Allocation of DCs and Courier Services to Markets

\begin{tabular}{|c|c|c|c|c|c|c|c|c|c|c|}
\hline Decision on PCs & \multicolumn{10}{|c|}{ Each PC $(1,2$, and 3$)$ assigned to supply regions $1,2,3,4$ and relevant markets } \\
\hline Regions & 1 & \multicolumn{3}{|c|}{2} & \multicolumn{2}{|c|}{3} & \multicolumn{2}{|c|}{4} & 5 & \multirow{2}{*}{$\begin{array}{r}\text { Remarks } \\
\text { No DC in Region } 5\end{array}$} \\
\hline $\begin{array}{l}\text { Assignment of DCs to } \\
\text { Regions }\end{array}$ & 1 & 2 & 3 & 5 & 4 & 7 & 6 & 8 & 0 & \\
\hline \multirow{3}{*}{$\begin{array}{l}\text { Assignment of markets to DCs } \\
\text { (Based on NS=3) }\end{array}$} & 11 & 9 & 3 & 7 & 1 & 4 & 6 & 2 & & \multirow[t]{3}{*}{ Market 5 not allocated } \\
\hline & 20 & 10 & 23 & 13 & 8 & 17 & 15 & 12 & & \\
\hline & 25 & 14 & 24 & 21 & 19 & 18 & 22 & 16 & & \\
\hline Decision on Courier Services & \multicolumn{10}{|c|}{ Courier service 4 to supply products to market 5 directly from PC 3} \\
\hline
\end{tabular}

Table 6 Typical data on transportation and distribution of product 1

\begin{tabular}{|c|c|c|c|c|c|c|c|c|}
\hline \multirow{4}{*}{$\begin{array}{l}\text { Transported } \\
\text { Products } \\
\text { From } \\
\text { PCs }\end{array}$} & \multicolumn{8}{|c|}{ Transportation and distribution of product 1 to Regions corresponding to the results in Table 5} \\
\hline & \multicolumn{2}{|c|}{1} & \multicolumn{6}{|c|}{2} \\
\hline & \multicolumn{2}{|c|}{ DC in Region 1} & \multicolumn{6}{|c|}{ DCs in Region 2} \\
\hline & \multicolumn{2}{|c|}{1} & \multicolumn{2}{|c|}{2} & \multicolumn{2}{|c|}{3} & \multicolumn{2}{|c|}{5} \\
\hline 1 & \multicolumn{2}{|c|}{11,797} & \multicolumn{2}{|c|}{0} & \multicolumn{2}{|c|}{10,853} & \multicolumn{2}{|c|}{0} \\
\hline 2 & \multicolumn{2}{|c|}{0} & \multicolumn{2}{|c|}{4,790} & \multicolumn{2}{|c|}{0} & \multicolumn{2}{|c|}{4,155} \\
\hline 3 & \multicolumn{2}{|c|}{0} & \multicolumn{2}{|c|}{0} & \multicolumn{2}{|c|}{2,572} & \multicolumn{2}{|c|}{5,652} \\
\hline & \multicolumn{2}{|c|}{ DC 1 to markets } & \multicolumn{2}{|c|}{ DC 2 to markets } & \multicolumn{2}{|c|}{ DC 3 to markets } & \multicolumn{2}{|c|}{ DC 5 to markets } \\
\hline & markets & & markets & & markets & & markets & \\
\hline & 11 & 2,969 & 9 & 648 & 3 & 2,415 & 7 & 2,862 \\
\hline & 20 & 4,612 & 10 & 1,763 & 23 & 6,160 & 13 & 5,655 \\
\hline & 25 & 4,216 & 14 & 2,379 & 24 & 4,850 & 21 & 1,290 \\
\hline Total & & 11,797 & & 4,790 & & 13,425 & & 9,807 \\
\hline
\end{tabular}

For the model results presented in Tables 5 and $\mathbf{6}$, the total cost turns out to be $\$ 84.841 \mathrm{M}$ of which $\$ 1.596 \mathrm{M}$ was spent on transportation and distribution of the products, and
$\$ 92,670$ was spent on the direct supply to market 5 from PC 3 using courier service 4 (see Table 5).

The model results presented here are based on a 
specific set of data assumed for this numerical example. It is apparent that SC managers may explore what-if situations based on their own business practices. The model provides an effective tool for optimizing the overall cost while at the same time fulfilling market requirements in various regions using the available distribution modes.

\section{CONCLUSIONS}

The present research proposes an efficient business planning approach for two-echelon SCs to address changes in product demand, market size, and transportation and distribution requirements. The model includes flexibility consideration in terms of deciding the regions where the DCs will be located, the number and sizes of DCs to address customer density, and their requirements effectively. The research provides managerial insights to utilize procurement centers, selection of distribution modes, and the regions where the DCs are allocation based on specific business characteristics.

\section{REFERENCES}

Agatz, N.A.H., Fleishmann, M., van Nunan, J.A.E.E (2008). efulfillment and multichannel distribution- A review. European Journal of Operational Research 187(2), pp. 339-386.

Chen, Z.-L.,Vairakatarakis, G.L. (2005). Integrated scheduling of production and distribution operations. Management Science 51(4), pp. 614-628.

Dasci, A., Verter,V. (2001). A continuous model for productiondistribution system design. European Journal of Operational Research 129 (2), pp. 287-298.
Jayaraman, V., Pirkul, H. (2001). Planning and coordination of production and distribution facilities for multiple commodities. European Journal of Operational Research 133 (2), pp. 394-408.

Jayaraman, V., Ross, A. (2003). A simulated annealing methodology to distribution network design and management. European Journal of Operational Research 144(3), pp. 629-44.

Lasserre, F. (2004). Logistics and internet: transportation and region issues are crucial in the logistics chain. Journal of Transport Geography 12(1), pp. 73-84.

Liu, S., Papgeorgiou, L.G.(2013). Multi-objective optimization of production, distribution, and capacity planning of global supply chains in the process industry. Omega 41(2), pp. 369-382.

Lummus, R.R., Vokurka, R.J. (2002). Making the right efulfillment decision. Production and Inventory Management Journal 43 (1/2), pp. 50-55.

Manzini, R., Accorsi, R., Bortolini, M. (2014). Operational planning for distribution networks. International Journal of Production Research 52(1), pp. 89-116.

Simchi-Levi, D. (1992). Hierarchical planning for probabilistic distribution planning in Euclidean spaces. Management Science 38(2), pp. 198-211.

Thomas, A.R., Wilkinson, T.J. (2006). The outsourcing compulsion. MIT Sloan Management Review 48(1), pp. 914.

Vidal, C., M. Goetschalckx, M. (1997). Strategic productiondistribution models: a critical review with emphasis on global supply chain models. European Journal of Operational Research 98 (1), pp. 1-18.

Yan, R., Guo, P.,Wang, J., Amrouchi, N. (2011). Product distribution and coordination strategies in a multi-channel context. Journal of Retailing and Consumer Services 18(1), pp. 19-26.

Dr. Kanchan Das is an Associate Professor in the Technology Systems Department of East Carolina University, North Carolina, USA. He received his $\mathrm{PhD}$ in Industrial Engineering from the University of Windsor, Ontario, Canada. His research interests include mathematical modeling of cellular and flexible manufacturing systems, reliability consideration in the design of cellular manufacturing systems, design and planning of supply chain management. He also conducts research on humanitarian logistics planning. His current research foci include sustainability considerations, risk management, and resiliency planning in supply chain design and management. He is a member of INFORMS and Institute of Industrial Engineers.

Dr. Reza Lashkari is Professor (Emeritus) of Industrial Engineering at the University of Windsor, Ontario, Canada. He received his MSc and $\mathrm{PhD}$ in Industrial Engineering from Kansas State University, USA, and B.Sc. in Electrical Engineering from the University of Tehran, Iran. His research interests include modelling and analysis of supply chain networks, modelling of cellular manufacturing systems, and reliability engineering, and more recently, modelling the logistics systems for humanitarian disaster relief. Dr. Lashkari is on the editorial board of Production and Inventory Management Journal and Operations and Supply Chain Management: An International Journal, and is a registered Professional Engineer in Ontario. 